$1-1-2021$

Repair of vesicouterine fistula by not using traditional O' connor method

Lubna Razzak

Raheela Mohsin Rizvi

Follow this and additional works at: https://ecommons.aku.edu/

pakistan_fhs_mc_women_childhealth_obstet_gynaecol

Part of the Obstetrics and Gynecology Commons 


\title{
Repair of vesicouterine fistula by not using traditional O' connor method
}

\author{
Lubna Razzak, Raheela Mohsin Rizvi
}

\begin{abstract}
A 25-year-old female patient visited our clinic with complaint of cyclic haematuria. She had previous two Caesarean Sections at a secondary care hospital. Her complete urinalysis showed abundant red blood cells. Through computed tomography a fistula tract between the posterior wall of the bladder and the anterior wall of the lower uterine segment was diagnosed. The Cystoscopy revealed a fistulous opening with a diameter of nearly 1.5 $\mathrm{cm}$ localized between the bladder and uterine cavity. Fistulae was repaired by abdominal approach without transection of bladder. Surgery was performed by mobilization of bladder and wide anterior uterine dissection. A $2 \mathrm{~cm}$ defect in the lower uterine segment was identified and was closed with 0 polyglycolic acid suture. Bladder defect was repaired in two layers and omental tissue flap was placed between the two surfaces. At 6 months follow the up patient was asymptomatic.
\end{abstract}

Keywords: cyclic menouria; vesicouterine fistulas; Youssef's syndrome.

\section{DOI: https://doi.org/10.47391/JPMA.019}

\section{Introduction}

Vesicouterine fistulae (VUF) is an iatrogenic abnormal communication developing between the urinary bladder and the uterus or cervix. Among urogenital fistulae, the incidence of vesico-uterine fistulae is reported as $1 \%$ to $9 \% 1$ and $83-88 \%$ of these are associated with lower-segment Caesarean Sections. ${ }^{2}$ The classic presentation of a vesicouterine fistula,described as Youssef syndrome is characterized by cyclical haematuria, amenorrhoea and urinary incontinence. ${ }^{3}$

\section{Case Presentation}

A 25-year-old patient presented at the outpatient department of Aga Khan University Hospital, Karachi on October 12, 2017 with complaint of cyclic haematuria. She had previous two Caesarean Sections at a secondary care hospital. During her last surgery she had intensive postoperative haematuria, which was treated by retaining an indwelling catheter for a month, expecting

Department of Obstetrics and Gynaecology, Aga Khan University Hospital, Karachi, Pakistan.

Correspondence: Raheela Mohsin Rizvi. e-mail: raheela.mohsin@aku.edu
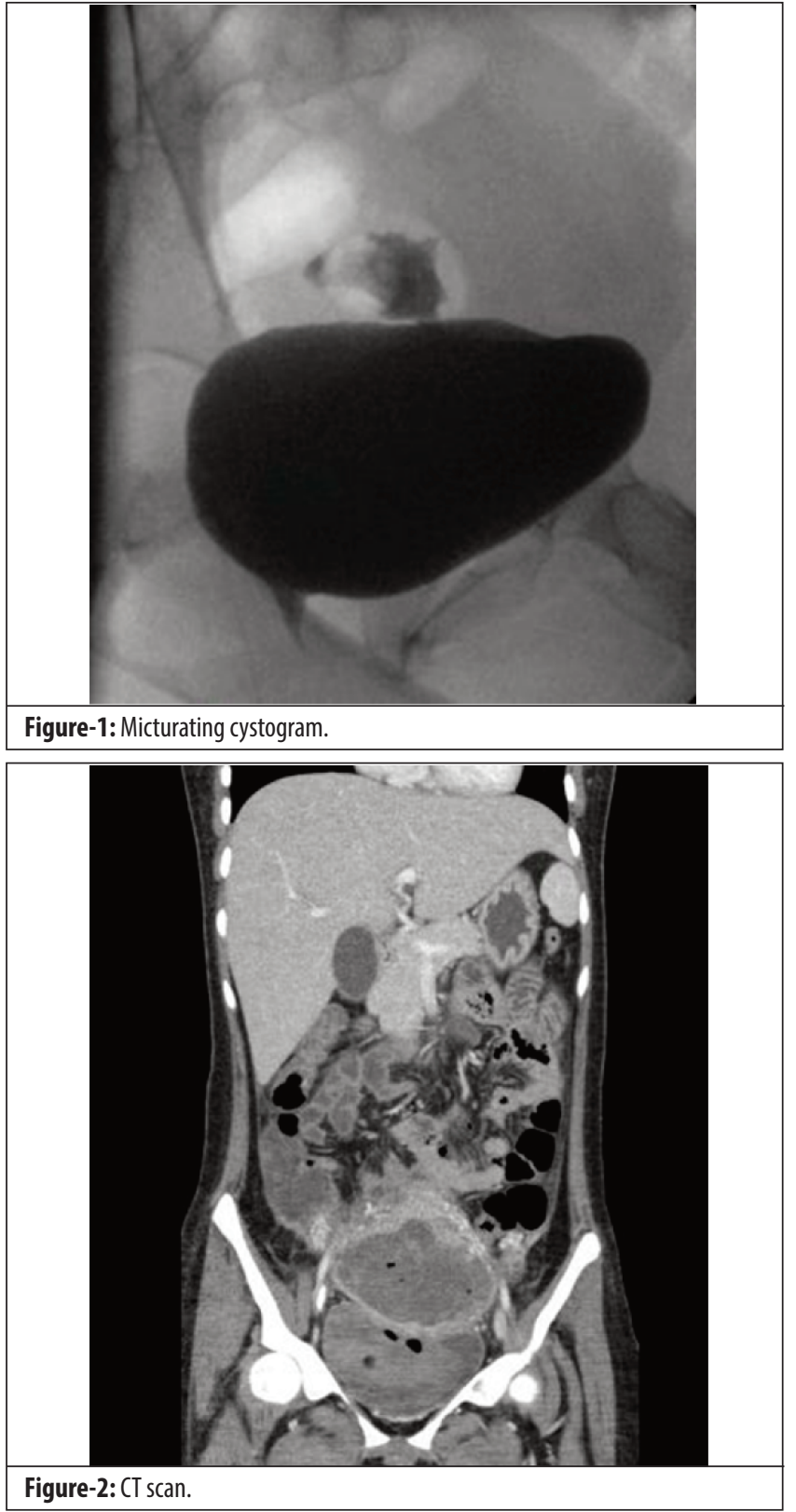

spontaneous closure of VU fistulae. She had no complaints suggesting recurrent urinary tract infection and incontinence. Her gynaecological examination was unremarkable except observation of red urine cyclically. Her complete urinalysis showed abundant red blood cells however her urine culture revealed no growth. Micturating cystogram was performed which showed an abnormal 
communication between the uterine cavity and the urinary bladder (Figure-1). Computer tomography (CT) with contrast showed a fistula tract between the anterior wall of the uterus and the posterior wall of the bladder at the level of lower uterine segment (Figure-2).

Patient gave an informed consent for examination under anaesthesia, cystoscopy and fistulae repair procedure. Cystoscopy revealed a fistulous opening with a diameter of nearly $1.5 \mathrm{~cm}$ on the posterior wall of bladder, rest of bladder mucosa, ureteric orifices and bladder capacity were normal. Both ureters were stented. Surgical technique using transabdominal approach was used for layered closure of fistulae using omental flap. Bladder was seen adherent to lower uterine segment. A wide anterior uterine dissection was performed to mobilize the bladder. Bladder cavity was inspected and fistulous opening was enlarged to around $2 \mathrm{~cm}$ after dissection. Bladder wall was closed in two layers using polyglycolic 2/o, omental tissue flap was pulled and placed between the two surfaces and uterine defect closed with 0 polyglycolic acid sutures. An intraoperative retrograde filling with methylene blue was performed to confirm watertight closure. For two weeks postoperatively, indwelling catheter was left in situ. She remained asymptomatic till 12 months of follow up in our clinic postoperatively. Her menstrual cycles were normal and she had no lower urinary tract symptoms.

\section{Discussion}

A rise in Caesarean Sections rate have led to an increase in the number of cases of genitourinary fistulae. ${ }^{4}$ The clinical presentation of uterovesical fistulae may vary. It usually presents as urinary incontinence, amenorrhoea, and cyclic haematuria but may present as secondary infertility and miscarriage during the first trimester. ${ }^{2}$

The factors that lead to the formation of VUF includes difficulty or inadequate mobilization of the bladder from the lower uterine segment, manual removal of the placenta, forceps vaginal delivery, placenta percreta, aberrant sutures in attempt to achieve haemostasis, uterine rupture and previous Caesarean Section. ${ }^{5}$ An unrecognized bladder injury might persist and lead to a VUF. "Menouria" was first described by Youssef in $1957 . .^{6}$ On the basis of routes of menstrual flow Jo'zwik proposed classification of VUF into three types. Type I, known as Youssef's syndrome is described as a triad of menouria, amenorrhoea, and without incontinence of urine.7 Type II is associated with menstrual blood flow via both the bladder and vagina. Normal vaginal menstrual flow and no menouria are characterized as type III.

The fistula is usually reported between the anterior lower uterine segment or rarely the cervix and the supra-trigonal part of the posterior bladder wall. The fistula that presents above the internal cervical os does not present as urinary incontinence because of the functional valve mechanism of the isthmic sphincter which maintains sufficient pressure to prevent urinary leakage from the vagina. ${ }^{2}$ When the fistula presents below internal cervical os, total vaginal urinary leakage occurs. Normally, the intravesical pressure during the filling phase rarely exceeds $20 \mathrm{~cm} \mathrm{H}_{2} \mathrm{O}$ but with detrusor muscle contraction in voiding phase, it rises up to $50 \mathrm{~cm} \mathrm{H} \mathrm{H}_{2} \mathrm{O}$. Intrauterine pressures are higher than the pressures in the bladder and vary with phases of the menstrual cycle. Intrauterine pressures during the proliferative phase and secretory phase are 35 to $70 \mathrm{~cm}$ $\mathrm{H}_{2} \mathrm{O}$ and 55 to $100 \mathrm{~cm} \mathrm{H}_{2} \mathrm{O}$ respectively, whereas during menstruation intrauterine pressures are $130-160 \mathrm{~cm} \mathrm{H}_{2} \mathrm{O}{ }^{2}$

The diagnosis of vesicouterine fistulae can be made through cystoscopy, intravenous pyelography, hysterography, computed tomography (CT) or magnetic resonance imaging $(\mathrm{MRI})$. Literature showed variable results with the uses of intravenous urogram and cystometrogram whereas transabdominal ultrasound has shown sensitivity of $29 \%$ in the diagnosis of genitourinary fistulae. CT was found to be a valuable tool in the diagnosis of a VUF. 8 In our case we used CT scan for diagnosis of a VUF.

Conservative management is an option for early or immediate postpartum phase with continuous bladder drainage of atleast 4-6 weeks. Five percent success rate has been reported for spontaneous healing of VUF with conservative management. ${ }^{3}$ Exogenous Hormonal treatment induced amenorrhoea, allows the fistula tract to close and the majority specify a period of 6 months for its treatment. 9 The definitive treatment is surgical management with preferred route of transabdominal approach.The choice of surgical management depends on the preservation of fertility or hysterectomy and bladder closure. For a woman having reproductive wishes, as in our case, uterine-sparing surgery is to be considered.2 Laparoscopic approach for repair of VUF has also been considered. Its advantages are quicker recovery convalescence, short hospital stay, good cosmetic results, and success rates are similar to open abdominal surgery. ${ }^{10}$ In literature we found UV fistula repair by longitudinal dissection of bladder using $\mathrm{O}^{\prime}$ Conor method. It has been observed that this procedure is associated with detrusor injury, bladder scarring, reduced capacity and de novo long standing lower urinary tract symptoms (LUTS). 11,12 We performed dissection between the lower segment of uterus and the bladder, and preferred layered closure of fistulae using omental flap as by Basatac. ${ }^{13}$

In subsequent pregnancies careful monitoring will be 
required, as there is a small but potential risk of scar dehiscence and/or recurrent fistula formation. ${ }^{14}$ After UVF repair, next delivery by Caesarean Sections has been recommended.15 To minimize the risk of fistulae formation, meticulous attention to surgical principles, and careful dissection of the lower uterine segments should be carried out. ${ }^{16}$

\section{Conclusions}

We have reported a new surgical technique for vesicouterine fistulae repair without opening the bladder across its entire length. The patient had an uneventful surgery and good postoperative recovery.

\section{Disclaimer: None.}

\section{Conflict of Interest: None.}

Funding Sources: None.

\section{References}

1. Hadzi Djokic JB, Pejcic TP, Colovic VC. Vesicouterine fistula: report of 14 cases. Int Urol Nephrol. 2002; 34:335-44.

2. Porcaro AB, Zicari M, Antoniolli SZ, Pianon R, Monaco C, Migliorini F. Vesicouterine fistulas following cesarean section Report on a case, review and update of the literature. Int Urol Nephrol. 2002; 34:33544.

3. Rajamaheswari N, Chhikara AB. Vesicouterine fistulae: our experience of 17 cases and literature review. Int Urogynecol J. 2013; 24:275-9.

4. Karaltı MO, Tınar Ş, Öztürk NT, Öztürk DC. A case with vesicouterine fistula: mini review. Arch Gynecol Obstet. 2012; 285:667-70.
5. Yossepowitch O, Baniel J, Livne PM. Urological injuries during cesarean section: intraoperative diagnosis and management. J Urol. 2004; 172:196-9.

6. Saikat Bhattacharjee, Uttara Aiyer Kohli, Atul Sood, STripathy, Mihir Gupta, et al. Vesicouterine fistula: Youssef's syndrome. Med J Armed Forces India. 2015; 71:S175-7.

7. Jozwik M, Józwik M. Clinical classification of vesicouterine fistula. Int J Gynaecol Obstet. 2000; 70:353-7.

8. Abou-El-Ghar ME, El-Assmy AM, Refaie HF, El-Diasty TA. Radiological diagnosis of vesicouterine fistula: role of magnetic resonance imaging. J Magn Reson Imaging. 2012; 36:438-42.

9. DiMarco CS, DiMarco DS, Klingele CJ, Gebhart JB. Vesicouterine fistula: a review of eight cases. Int Urogynecol J Pelvic Floor Dysfunct. 2006; 17:395-9.

10. Ramalingam M, Senthil K, Pai M, Renukadevi R. Laparoscopic repair of vesicouterine fistula-a case report. Int Urogynecol J Pelvic Floor Dysfunct. 2008; 19:731-3.

11. Agarwal MM, Raamya SM, Mavuduru R, Mandal AK, Singh SK. Voiding dysfunction after repair of giant trigonal vesicovaginal or urethrovesicovaginal fistulae: a need for long-term follow-up. Indian J Urol. 2012; 28:405-8.

12. Yuh LM, Rothschild JG. Complications and Long-Term Sequelae of Bladder Fistula Repair. Curr Bladder Dysfunct Rep. 2016; 11:317-24.

13. Basatac C, Cicek MC. Vesicocutaneous fistula treatment by using omental flap interposition. J Surg Case Rep. 2015; 2015:rjv004.

14. Singh V, Mandhani PA, Mehrotra S, Sinha RJ. Laparoscopic repair of vesicouterine fistula: a brief report with review of literature. Urol J. Spring 2011; 8:149-52.

15. Rajamaheswari N, Chhikara AB. Vesicouterine fistulae: our experience of 17 cases and literature review. Int Urol Nephrol. 2013; 24:275-9.

16. Antonio B Porcaro, Marianna Zicari, Stefano Zecchini Antoniolli, Romeo Pianon, Carmelo Monaco, Filippo Migliorini, et al. Vesicouterine fistulas following cesarean section Report on a case, review and update of the literature. Int Urol Nephrol. 2002; 34:335-44. 